\title{
The Wage Effect of Informal Sector in Developing Countries
}

\author{
Tchakounté Njoda Mathurin ${ }^{1}$, Abdoul Karim ${ }^{2}$ \\ ${ }^{1}$ Faculty of Economic Sciences and Management, University of Ngaoundéré, Ngaoundéré, Cameroon \\ ${ }^{2}$ Faculty of Economic Sciences and Management, University of Maroua, Maroua, Cameroon
}

Email address:

mtchakou@yahoo.fr (T. N. Mathurin), abdoulkarim.mahamoudou@yahoo.fr (A. Karim)

\section{To cite this article:}

Tchakounté Njoda Mathurin, Abdoul Karim. The Wage Effect of Informal Sector in Developing Countries. Journal of World Economic Research. Special Issue: The Globalization and Economic Structure Changes. Vol. 4, No. 5-1, 2015, pp. 53-62.

doi: $10.11648 /$ j.jwer.s.2015040501.17

\begin{abstract}
A theoretical model of wage effect of informal sector has been developed with special reference of informal sector. The implication of the theory in the context of a model of a competitive labour market where the wage impact of informal employment is influenced by such factors as the elasticity of product demand, the rate at which the consumer base as workers enter informal sector, the elasticity of supply of capital, and the elasticity of substitution across inputs of production. The analysis reveals that the short-run wage effect of informalisation is negative in a wide array of possible scenarios, and that even the long-run effect of informalisation is positive, but may be negative if the impact of informalisation on the potential size of the consumer base is smaller than its impact on the size of the workforce. These predictions are then empirically validated using two different measures of the size of the informal sector. The results are shown to be robust with respect to a variety of econometric regressions.
\end{abstract}

Keywords: Informal Sector, Real Wage, Labour Market, Competitive Market

\section{Introduction}

Data from a number of developing countries have indicated a widespread trend toward greater

informalisation of economies (Heintz and Pollin, 2003; Ghose, 2003; Henley et al., 2007; and Rufer and Knight, 2007). Most developing and emerging economies are characterized by the presence of informal employment. While many definitions exist, an informal, unregulated labor market can be seen as one where workers are unregistered and not liable to taxes and contribution, not subject to labor market regulations, excluded from social security coverage (pension, benefits), etc.

The growing share of the informal sector at the expense of the formal sector raises serious questions and concerns. For example, the existence of an informal sector must have crucial implications on the earnings structure. This situation has often been cited as a central factor underlying wage inequality 1 , persistent poverty and labor market

1 In Sub-Saharan Africa, for example, $68 \%$ of the labor force engage in agricultural activities and many of these laborers do not earn a wage but, instead, survive by selling or consuming their own farm output (World Bank, 1996). For inefficiencies. According to the traditional view (Fields, 1975, Dickens and Lang, 1985), workers enter informality to escape unemployment and because they are rationed out of the formal sector as a result of an overly regulated labor market. They earn less than identical workers in the formal sector - wages in the latter are set above market-clearing prices because of minimum wages, higher unionization or efficiency-wage explanations. If labor markets are competitive, wage equalization should eventually occur - or remaining wage gaps could be justified by compensating differentials in one or the other sector.

An informal wage penalty may arise if labor market regulation (minimum wages, higher unionization) not only keeps a large part of the labor force out of formal employment but also pushes up formal sector wages above market-clearing levels. It may also derive from lower bargaining power among informally employed workers (Carneiro and Henley, 1998). These situations often - but not always - characterize informal workers in firms which are

this reason, Blunch et al. (2001) also proposed a disaggregation of the informal sector between non-wage employment (which comprises the self-employed and those working in family businesses) and wage employment (which includes both regular and casual workers). 
themselves unregistered. In that case, an informal wage penalty may also be the result of a firm size effect. Indeed, larger firms pay more and, at the same time, are more likely to be formal because of larger exposure to the risk of being caught defaulting (Badaoui et al., 2010).

More precisely, informal labour market characterized by competitive wage formation rather than unionized process of negotiations has emerged as an important institution in the entire developing world. When the size of the informal sector in the developing countries is increasing at a brisk pace, it is therefore important to know how the rise of informal sector affects the real wage. Labour market rigidities usually lead to the hiring of informal workers who are hired at a wage rate lower than the one prevailing in the formal sector, but the existence of an informal sector allows some degree of labour market flexibility even at the cost of encouraging an environment where people are employed at a low wage and under poor working conditions. What happens to real wages in the informal sector after the expansion of informalisation in that sector? Theory predicts that informal sector wages will fall when the supply of labor to the informal sector rises and there is no matching rise in demand. But some empirical evidence on wages in the informal manufacturing sector shows that real informal wages have been on the rise even in a situation when the organized sector has been lamenting jobless growth (Marjit and Maiti, 2006).

In this paper we present evidence of wage decrease in short-run as a result of informal sector increase from a panel of countries developing between 1990 and 2015. Our results show a robust and sizable of this effect. Our central estimates suggest that, in a country that has some informality dynamics or switches from non-informality to informality, increase in real wage following a $1 \%$ informalisation is $-0.679 \%$ in short-run with an positive impact of $18.6 \%$ in long-run.

There are several assumptions in estimating the impact of informality on real wage. First, the wage effect of formalisation is weaker (i.e., less negative) the easier it is to substitute labor and capital. Second, the wage effect of informalisation is weaker the more "important" labor is in the production process. Third, the wage effect of informalisation is weaker the more elastic the supply of capital. Fourth, the wage effect of informalisation is stronger the more elastic product demand. Fifth, the wage effect of informalisation is weaker the greater the impact of informalisation on the size of the consumer base relative to its impact on the size of the workforce.

In this paper, we make progress in addressing all four of these assumptions. First, we build on the important work by International Labour Organization (ILO) and the International Conference of Labour Statisticians (ICLS) to develop employment and real wage measures of informal sector purged of spurious changes in informality scores available in the standard datasets, and rely on this measure for most of our analysis.

Second, we include country fixed effects in all specifications in order to remove the impact on wage variation of fixed country characteristics potentially correlated with informality. We also include year fixed effects to remove any common global changes in informality that may be correlated with real wage. Third, we allow for and estimate serially correlated dynamics in $(\log )$ real wage using a strategy that permit to control for lags of real wage in linear regressions. Fourth, in addition to controlling for a full set of country and year fixed effects, we use an Instrumental Variables (IV) strategy to overcome omitted variable bias. Our identification assumption is that informalisation in a country spreads to other less-informal countries in the same region, but does not have a direct differential impact on wage change in these countries.

Our baseline strategy to deal with the confounding effects of informality is to include a sufficient number of lags of real wage in annual panel data regression with country and year fixed effects. Ordinary Least Squares (OLS) or Generalized Method of Moments (GMM) estimates lead to fairly stable estimates of the dynamics of real wage. Our instrumentalvariables (IV) strategy uses our regression-based correction for real wage dynamics and exploits exogenous variation in regional waves of informalisation to identify the effect of informality (essentially comparing countries that are otherwise similar but are affected by differential waves of regional informalisation).

The rest of the paper is organized as follows. The next section presents the prior theoretical framework on the relationship between wage and informal sector. Section 3 describes hypothesis, provides data descriptions for our sample, and analysis for the baseline results, which use a linear model for controlling for wage dynamics. The model is estimated using the standard within estimator and various GMM estimators. This section also presents a variety of robustness checks. Section 4 concern concluding remarks.

\section{Theoretical framework}

\subsection{A Simple Model}

Let a simple model of the labor market with aggregate good, $Q$, is produced using a Cobb-Douglas production function that combines a homogeneous labor input $(L)$ and capital $(K)$, hence $Q=K^{\alpha} L^{1-\alpha}$. It turns out that the key insights provided by this model - including a range of numerical values for the wage effect of informal sector carry through to more complicated models that allow for a generalized production technology or for heterogeneous labor, as well as for various feedback effects.

To fix ideas, consider first a model where the product price $p$ is fixed - one can think of $p$ as the "numeraire" or perhaps it is set in the global market. In a competitive market, each input will be paid its value of marginal product:

$$
w=p(1-\alpha) K^{\alpha} L^{1-\alpha} \text { and } r=p \alpha K^{\alpha-1} L^{1-\alpha},
$$

where $w$ is the wage rate and $r$ is the price of capital.

In this simple framework, the parameter $\alpha$ gives capital's share of income, or $s_{K}$. It is useful to consider two situations: the short-run and the long-run. By definition, the capital stock is fixed in the short-run and the price of capital is fixed in the long-run. Suppose an informal worker influx increases the size of the workforce. By differentiating equation (1), it is easy to show that: 


$$
\left.\frac{d \log w}{d \log L}\right|_{d K=0}=-S_{K} \text { and }\left.\frac{d \log w}{d \log L}\right|_{d r=0}=0 .
$$

The term $\frac{d \log w}{d \log L}$ is called the "wage elasticity" of informal sector. The Cobb-Douglas technology not only provides a simple expression for this wage elasticity, but suggests a range of numerical values as well. It is well known that labor's share of income in Sub-Saharan (developing) countries $\left(s_{L}=1-s_{K}\right)$ has hovered around 0.25 for many decades. This implies that the short-run wage elasticity is -0.75 . In the long-run, the capital stock adjusts fully and the wage elasticity exactly equals 0.0 . In other words, to the extent that the Cobb-Douglas technology is a reasonable approximation of the aggregate labor market, one would expect the wage elasticity to lie between 0.0 and -0.25 , depending on the extent to which capital has adjusted to the presence of the informal worker influx.

It is worth emphasizing that the absence of a wage effect from informal sector in the long-run is a general property of any model with Constant Returns to Scale (CRS) production function. A CRS production function implies that input prices depend only on the capital/labor ratio. The long-run assumption that the price of capital is constant is effectively building in the restriction that the capital/labor ratio is also constant. If informal workers increase the size of the workforce by $10 \%$, the capital stock must eventually also increase by $10 \%$. In the end, the wage returns to its preinformalisation level.

We can extend the precedent model 2 by taking two goods: one good is produced domestically, while the other good is imported. The good $q$ is produced domestically, and the good $y$ is imported. By Dixit and Norman (1980), we initially assume that the price of the imported good $y$ is set in the global marketplace (or, alternatively, that it is produced at constant marginal cost). In this context, the price of $y$ is the numeraire and set to unity. Each person $j$ in the domestic labor market has a quasi-linear utility function given by:

$$
U(y, q)=y+g_{j}^{*} q^{\xi}
$$

where the weight $g^{*}$ reflects the consumer's relative preference for the domestic good and may be different for different consumers (or different groups of consumers). The utility function will be quasi-concave only if $0<\xi<1$. As we show below, this restriction has implications for the magnitude of the price elasticity of demand. Let $Z$ be the consumer's income. The budget constraint is then given by: $Z=y+p q$. Utility maximization implies that the product demand function for the domestic good is: $q_{j}=g_{j} p^{-1 /(1-\xi)}$, where $q_{j}$ is the amount of the good consumed by consumer $j$; and $g_{j}$ is the rescaled person-specific weight. The quasi-linear

\footnotetext{
2 We relax the assumption that the elasticity of substitution between labor and capital in the production of the domestic good is unity. Finally, we allow for the possibility of changes in product demand both because informalisation may have changed the price of the domestically produced product (encouraging consumers to change their quantity demanded) and because workers themselves will consume the product. If we explicitly introduce a supply curve of domestic capital, the resulting model has much in common with derivations of Marshall's rules of derived demand (for much details, see Kennan, 1998).
}

functional form for the utility function implies that the consumer's demand for the domestic product does not depend on his income.

Three types of persons consume good $q$ : domestic workers, domestic capitalists, and consumers in other countries. Let $C_{L}$ be the number of domestic workers, $C_{K}$ be the number of domestic capitalists, and $C_{X}$ be the number of consumers in the "rest of the world." We assume that each type of consumer has the same quasi-linear utility function in (3), but that the weighting factor $g$ may differ between domestic and foreign consumers. The total quantity demanded by domestic consumers $\left(Q_{D}\right)$ and foreign consumers $\left(Q_{X}\right)$ is then given by: $Q_{D}=g_{D}\left(C_{L}+C_{K}\right) p^{-1 /(1-\xi)}$ and $Q_{X}=g_{X} C_{X} p^{-1 /(1-\xi)}$.

Balanced trade requires that expenditures on the imported good $y$ equal the value of the exports of $\operatorname{good} q$ :

$$
w L+r K-g_{D}\left(C_{L}+C_{K}\right) p^{-1 /(1-\xi)}=g_{X} C_{X} p^{-1 /(1-\xi)},
$$

where $(w L+r K)$ gives the total payment to domestic factors of production $L$ and $K$. In a competitive market, the payment to each factor of production equals its value of marginal product. If the production function is linear homogeneous, Euler's theorem implies that the expression in (4) can be rewritten as: $\quad w L+r K=p\left(Q_{L} L+Q_{K} K\right)=p Q=$ $\left[g_{D}\left(C_{L}+C_{K}\right)+g_{X} C_{X}\right] p^{-1 /(1-\xi)}$. Where $Q_{i}$ is the marginal product of factor $i$. It follows that aggregate market demand for the domestic good is given by:

$$
Q=C p^{-1 /(1-\xi)},
$$

where $C=g_{D}\left(C_{L}+C_{K}\right)+g_{X} C_{X}$, the (weighted) number of consumers3.

A crucial question in evaluating the impact of informality on the domestic labor market is: How does an informality-induced increase in the size of the workforce affect the size of the consumer base? Let $C(L)$ be the function that relates the number of consumers to the number of workers, and let $\varphi=d \log C / d \log L$. An important special case occurs when the elasticity $\varphi=1$, so that the informal influx leads to a proportionately equal increase in the (weighted) number of consumers and the number of workers. We shall refer to the assumption that $\varphi=1$ as the case of product market neutrality. The "neutrality," of course, refers to the fact that the informality-induced supply shift has the same relative impact on the size of the consumer base and the size of the workforce.

Note that it is easy to account for different product demand preferences between informal workers and formal one by allowing for non-neutrality, i.e., by allowing for deviations from unity in the elasticity $\varphi$. For instance, if informal workers tend to prefer the consumption of the imported good, an informal influx that increases the size of the workforce by $x$ percent would likely lead to a smaller percent increase in the number of "effective" consumers for the domestic good.

Equation (5) suggests that an informality-induced supply shift will have two distinct effects in the domestic labor

3 Note that the demand elasticity $(\mathrm{d} \log \mathrm{Q} / \mathrm{d} \log \mathrm{p})$ is greater than unity (in absolute value). This is an important implication of quasi-linear utility functions, and the restriction will be used to interpret some of the results presented below. 
market through product demand: First, the price of the domestic good might change, moving current consumers along the existing product demand curve; second, because informal workers are themselves "new" consumers, the market product demand curve will shift out and the magnitude of this shift will depend on $\varphi$.

It is analytically convenient to work out the model in terms of the inverse product demand function: $p=C^{\eta} Q^{-\eta}$, where $\eta$ is the inverse price elasticity of demand, with $\eta=1-\xi \geq 0$. Note again that the quasi-linear utility function restricts the inverse elasticity of demand $\eta$ to be smaller than 1 .

The production technology for the domestic product is given by the Constant Elasticity Substitution (CES) production function:

$$
Q=\left[\alpha K^{\delta}+(1-\alpha) L^{\delta}\right]^{1 / \delta},
$$

where $\delta \leq 1$. The elasticity of substitution between labor and capital is $\sigma=1 /(1-\delta)$. Note that the production function in (6) maintains the CRS assumption from the previous section.

Finally, the supply of domestic capital is given by the supply function: $r=K^{\lambda}$, where $\lambda \geq 0$, and is the inverse elasticity of supply of capital. The two special cases introduced in the previous section for the short-run and the long-run correspond to $\lambda=\infty$ and $\lambda=0$, respectively.

In a competitive market, input prices equal the value of marginal product:

$$
w=p(1-\alpha) C^{\eta} Q^{1-\delta-\eta} L^{\delta-1} \text { and } r=\alpha C^{\eta} Q^{1-\delta-\eta} K^{\delta-1},
$$

Let $d \log L$ represent the informality-induced percent change in the size of the workforce. By differentiating equation (7), allowing for the fact that the supply of capital is given by $r=K^{\lambda}$, it can be shown that:

$$
\frac{d \log w}{d \log L}=\frac{-\lambda(1-\delta-\eta) s_{K}}{(1+\lambda-\delta)-(1-\delta-\eta) s_{K}}-\frac{(1+\lambda-\delta) \eta(1-\varphi)}{(1+\lambda-\delta)-(1-\delta-\eta) s_{K}}
$$

Consider initially the special case of product market neutrality (i.e., $\varphi=1$ ), so that informality expands the size of the consumer pool by the same proportion as its expansion of the workforce. The wage elasticity in (8) then reduces to:

$$
\left.\frac{d \log w}{d \log L}\right|_{\phi=1}=\frac{-\lambda(1-\delta-\eta) s_{K}}{(1+\lambda-\delta)-(1-\delta-\eta) s_{K}} .
$$

Note that in the long-run $(\lambda=0)$, the wage elasticity goes to zero4.

Define $\eta^{*}$ to be the elasticity of product demand (i.e., $\eta^{*}=$ $1 / \eta)$. It is then easy to show that

$(1-\delta-\eta)>0$ implies that:

$$
\eta^{*}>\sigma
$$

In other words, even after allowing for a full response by all consumers in the product market, the wage effect of informality will be negative if there is incomplete capital

4 Note also that the denominator of equation (9) is unambiguously positive. In particular, $(1+\lambda-\delta)-(1-\delta-\eta) \mathrm{sK}=\lambda+(1-\delta) \mathrm{s} L+\eta \mathrm{sK} \geq 0$. The denominator is strictly positive if $\lambda>0$, or $\delta<1$, or $\eta>0$. As long as there is incomplete capital adjustment $(\lambda>0)$, therefore, the wage elasticity will be negative if $(1-\delta-\eta)>0$. adjustment and if it is easier for consumers to substitute among the available goods than it is for producers to substitute between labor and capital. This latter condition, of course, has a familiar ring in labor economics - as it happens to be identical to the condition that validates Marshall's second rule of derived demand5.

It turns out, however, that the condition in equation (10) can be independently corroborated within the context of the informality model presented in this point. In particular, recall that the quasi-linear utility function used to derive a consumer's product demand function restricted the inverse of the elasticity of product demand to be less than unity, hence $\eta^{*}>1$. Equation (10), therefore, is satisfied for the Cobb-Douglas production function, as well as for any production function that allows less substitution between labor and capital than the Cobb-Douglas. Hamermesh's (1993) survey of labor demand concludes that the Cobb-Douglas is a reasonably good approximation to the aggregate production function in developing countries and, if anything, the actual estimates of $\sigma$ may be slightly lower than 1.0 .

The restriction that $(1-\delta-\eta)>0$ is positive can also be derived as a second-order condition to the problem faced by a social planner trying to determine the optimal amount of informalty in the context of the current model. One important feature of the competitive market model presented in this point is that the wage-setting rule ignores the fact that an additional informal worker affects product demand, so that the marginal revenue product of an informal worker is not equal to his value of marginal product. Suppose a social planner internalizes this externality and wishes to admit the informal employment influx that maximizes gross domestic product net of any costs imposed by informalisation.

More precisely, the social planner wishes to maximize: $\Omega=p Q-M h=C^{\eta} Q^{1-\eta}-M h$, where $M$ gives the number of informal workers and $h$ gives the (constant) cost of admitting an additional informal workers (perhaps in terms of providing taxes, services, etc.). For simplicity, consider the case with product market neutrality. It is possible to show that the second-order conditions for this maximization problem are satisfied if: $(1-\eta)>0$ and $(1-\delta-\eta)>0$.

In short, as long as the social planner takes into account that the marginal revenue produced by an additional informal worker is not constant, the wage elasticity in equation (9) must be negative. Put differently, the scale effect resulting from informalisation - regardless of whether it occurs through an expansion of the capital stock or through an expansion in product demand - can never be sufficiently strong to lead to a wage increase. And, in fact, as long as capital adjustment is incomplete, the wage effect must be negative.

A vast number of special cases in the presence of product market neutrality can be obtained by evaluating equation (9) at specific values of the four parameters that determine the wage effect of informalisation (i.e., $\lambda, \eta, \delta$, and $s L$ ). For instance, it is easy to calculate the wage effect in the simple

5 An increase in labor's share of income leads to more elastic demand "only when the consumer can substitute more easily than the entrepreneur" (Hicks, 1932, p. 246). 
Cobb-Douglas economy considered in the previous point simply evaluate (9) after setting $\delta=0, \lambda=\infty, \eta=0$ for the short-run, and $\delta=0, \lambda=0$, and $\eta=0$ for the long-run.

It is equally easy to measure the size of the scale effect triggered by informality by considering the simple case of a Cobb-Douglas economy in the short-run. The wage elasticity in (9) then collapses to:

$$
\left.\frac{d \log w}{\operatorname{dlog} L}\right|_{\substack{\phi=1 \\ \delta=0 \\ \lambda=\infty}}=-(1-\eta) s_{K} .
$$

By contrasting this elasticity with the analogous effect in the one-good model presented in equation (2), it is easy to see that the scale effect of informality equals $\eta s K$. In the absence of the scale effect, the wage elasticity would equal -0.25 . If the inverse elasticity of product demand is 0.5 (implying a product demand elasticity of 2.0), the wage elasticity would fall to -0.15 . In other words, the short-run adverse effect of informalisation on the wage can be greatly alleviated through increased product demand - as long as the product demand elasticity is sizable.

It is important to emphasize that this negative wage impact can persist - even in the long-run - if the product market neutrality assumption does not hold. Consider, in particular, the non-neutral case where informalisation does not expand the size of the consumer base as rapidly as it expands the size of the workforce (i.e., $\varphi<1$ ). The second term in (8) is then negative and does not vanish as $\lambda$ goes to zero. In other words, the adverse wage effect of informalisation is larger because there are "too many" workers and "too few" consumers. This result has interesting implications for the economic effect of informalisation when informal workers share out a large fraction of their earnings to the other member of family in the form of distribution.

Moreover, the wage consequences of even slight deviations from product market neutrality can be numerically sizable. As an illustration, consider the long-run effects in a Cobb-Douglas economy. In the long-run, the first term in equation (8) vanishes and the wage elasticity is given by:

$$
\left.\frac{d \log w}{\operatorname{dlog} L}\right|_{\substack{\lambda=0 \\ \delta=0}}=\frac{-\eta(1-\varphi)}{1-(1-\eta) s_{K}}
$$

Suppose that $\varphi=0.90$, so that an informalisation-induced doubling of the workforce increases the size of the consumer pool by $90 \%$. Suppose again that the inverse elasticity of product demand $\eta$ is 0.5 . Equation (13) then predicts that the long-run wage elasticity of informality will equal -0.06 .

\subsection{Informality and Price}

The wage effect summarized in equation (8) gives the wage impact of informalisation in terms of the price of the imported product (i.e., the numeraire). It is also of interest to determine the impact of informalisation relative to the price of the domestically produced good. After all, informalisation has domestic product price effects both because the wage drops and because informal workers themselves shift the product demand curve outwards. By differentiating $p=$ $C^{\eta} Q^{-\eta}$ with respect to the informalisation-induced supply shift, it can be shown that the effect of informalisation on the domestic price is given by:

$$
\frac{d \log p}{d \log L}=\frac{\lambda \eta s_{K}}{(1+\lambda-\delta)-(1-\delta-\eta) s_{K}}-\frac{\eta(1-\varphi)\left[\lambda+(1-\delta) s_{L}\right]}{(1+\lambda-\delta)-(1-\delta-\eta) s_{K}} .
$$

Suppose that there is product market neutrality. The second term of (13) then drops out. informalisation has no price effect either in the long-run $(\lambda=0)$ or if the informal worker influx has no impact on the domestic product market $(\eta=0)$. However, equation (13) shows that informalisation must increase prices as long as the product demand curve is downward sloping and capital has not fully adjusted.

The prediction that domestic prices rise at the same time that wages fall seems counter-intuitive. However, it is easy to understand the economic factors underlying this result by simply differentiating the market product demand curve:

$$
\frac{d \log p}{d \log L}=\eta s_{K}\left(1-\frac{d \log K}{d \log L}\right)-\eta(1-\varphi)
$$

As long as there is product market neutrality, the price of the domestic good must rise whenever capital adjusts by less than the informalisation -induced percent shift in supply. The intuition is clear: In the absence of full capital adjustment, the informalisation -induced increase in domestic product demand cannot be easily met by the existing mix of inputs, raising the price of the domestic product.

An important question, of course, is: what happens to the real wage defined in terms of the price of the domestic product (or $w / p$ )? By combining results from equations (8) and (13), it is easy to show that the real wage elasticity of informalisation (defined as the wage effect relative to the change in domestic prices) is given by:

$\dot{w}=\frac{d \log (w / p)}{d \log L}=\frac{-\lambda(1-\delta) s_{K}}{(1+\lambda-\delta)-(1-\delta-\eta) s_{K}}=\frac{\eta(1-\varphi)(1-\delta) s_{K}}{(1+\lambda-\delta)-(1-\delta-\eta) s_{K}}$.

Note that if the product market neutrality assumption holds, the second term in (15) vanishes and informalisation must reduce the real wage as long as capital does not fully adjust. Note also that this result does not depend on the relative magnitudes of the elasticities of substitution and product demand. The negative impact of informalisation on the real wage is not surprising. After all, informalisation reduces the nominal wage and increases the price level simultaneously. To simplify the discussion, we shall refer to the elasticity in (15) as the real wage elasticity of informalisation.

In order to get a sense of the magnitude of the real wage elasticity, it is again instructive to refer back to the simplest example: a Cobb-Douglas economy in the short-run. If there is product market neutrality, it is easy to show that:

$$
\left.\frac{d \log (w / p)}{\operatorname{dlog} L}\right|_{\substack{\delta=0 \\ \phi=1 \\ \lambda=\infty}}=-S_{K} .
$$

The short-run real wage elasticity is identical to that implied by the simplest one-good

Cobb-Douglas model in equation (2). Even after the model accounts for the fact that informal workers increase the size of the consumption base proportionately and that informalisation -induced price changes move the pre-existing 
consumers along their product demand curve, the short-run wage elasticity is -0.25 .

The theory of factor demand, therefore, clarifies an important misunderstanding: the often-heard argument that the outward shift in product demand induced by informalisation will somehow return the economy to its preinformalisation equilibrium does not have any theoretical support. Instead, factor demand theory reveals that informalisation will inevitably have an adverse effect on the real wage. Put differently, the number of domestically produced widgets that the typical worker in the receiving country can potentially buy will decline as the result of the informal worker influx - even after one accounts for the fact that informal workers themselves will increase the demand for widgets. And, under some conditions, the decline in the number of widgets that can be purchased is exactly the same as the decline found in the simplest factor demand model that ignores the role of informal workers in the widget product market.

\section{Panel Data Results}

\subsection{Hypothesis}

Some wage hypothesis can be derived using Marshall's rules. As with Marshall's rules of derived demand, a great deal of insight into the underlying economics can be obtained by differentiating the real wage elasticity in equation (15) with respect to the parameters that determine its value. But some caution is required when interpreting these derivatives. Labor's share of income is not constant unless the production function is Cobb-Douglas. To fix ideas, we focus on the case of product market neutrality. It is also useful to conduct this exercise in terms of the actual elasticity of substitution, the elasticity of product demand, and the elasticity of supply of capital (rather than some transformation or inverse of the relevant elasticity). In particular, note that $\sigma=\frac{1}{1-\delta}$, and define the price elasticity of demand as $\eta^{*}=\frac{1}{\eta}$; and the elasticity of supply of capital as $\lambda^{*}=\frac{1}{\lambda}$. Since the long-run impact of informalisation on the real wage is numerically equal to zero, we focus on the case of $\lambda^{*}<\infty$. It can then be shown that:

$$
\frac{\partial \dot{w}}{\partial \sigma}>0, \frac{\partial \dot{w}}{\partial s_{L}}>0, \frac{\partial \dot{w}}{\partial \lambda^{*}}>0, \text { and } \frac{\partial \dot{w}}{\partial \eta^{*}}>0
$$

The partial derivatives reported in equation (17) ignore the feedback effects that occur through changes in $s_{L}$ (Pemberton, 1989). The easiest way to prove the rules is to convert the wage elasticities defined either in equation (8) or (15) into formulas that depend on the actual values of the elasticities rather than on their transformation. For example, in terms of the primitive parameters, equation (15) can be written as:

$$
\dot{w}=\frac{-\left[\eta^{*}+\lambda^{*}(1-\phi)\right] s_{K}}{\eta^{*}\left(\lambda^{*}+\sigma\right)-\lambda^{*}\left(\eta^{*}-\sigma\right) s_{K}} .
$$

The rules are easily obtained by partially differentiating expression (18). Therefore, we can express these five assumptions: (i) The wage effect of formalisation is weaker (i.e., less negative) the easier it is to substitute labor and capital. If labor and capital are easily substitutable, the effective magnitude of the informalisation-induced supply shock is smaller for any particular informality influx. As a result, the adverse wage effect is weaker.

(ii) The wage effect of informalisation is weaker the more "important" labor is in the production process. This rule is most obvious in the original Cobb-Douglas results presented in equation (7). If labor were "unimportant", even a relatively small informal supply shock would have a disproportionately large effect.

(iii) The wage effect of informalisation is weaker the more elastic the supply of capital. Post- informalisation adjustments in the capital stock attenuate the initial wage impact. The easier it is for such capital adjustments to take place, the weaker will be the wage effect of informalisation.

(iv) The wage effect of informalisation is stronger the more elastic product demand. The scale effect is smaller the greater the elasticity of product demand because consumers would then substantially cut back their demand for the domestic good as the price rises. The smaller the scale effect, the larger the informalisation -induced real wage cut.

These rules were derived under the condition of product market neutrality. In the absence of neutrality, the informalisation context adds an interesting fifth rule:

(v) The wage effect of informalisation is weaker the greater the impact of informalisation on the size of the consumer base relative to its impact on the size of the workforce. The adverse wage impact of informalisation will obviously be much weaker if there are "few" workers and "many" consumers.

The partial derivative for this fifth rule is $\frac{\partial \dot{w}}{\partial \varphi}>0$. Note, however, that if $\varphi \neq 1$, the partial derivatives for the other rules will contain an additional term. The sign of this term will generally depend on whether $\varphi$ is less than or greater than 1 .

\subsection{Data and Variables}

We construct an annual panel every 5 years comprising 47 developing countries from 1990 to 2015, though not all variables are available for all countries in all periods. The endogenous variable is wage. In the present research, it refers to real average monthly wages of informal employees. To adjust for the influence of price changes over different time periods, wages from ILO are measured in real terms, i.e. the nominal wage data are adjusted for consumer price inflation in the respective country. Real wage growth refers to the year-on-year change in real average monthly wages of all informal employees.

Our two others main outcome variables are: GDP per person employed in informal sector and percentage of informal employees. The first variable, GDP per person employed in informal sector, is GDP divided by total employment in the informal economy. Purchasing power parity (PPP) GDP is GDP converted to 1990 constant international dollars using PPP rates. 
The second variable, percentage of informal employees6, represents persons employed in the informal sector as percentage of working age population.

When we examine mechanisms, we use tax rate, interest rate, Inflation consumer price, effective exchange rate index, and final consumption expenditure data, all from the World Development Indicators. Descriptive statistics for all variables used in the main sample are reported in Table 1.

Tax rate is total tax rate ( $\%$ of commercial profits) : It is the amount of taxes and mandatory contributions payable by businesses after accounting for allowable deductions and exemptions as a share of commercial profits. Taxes withheld (such as personal income tax) or collected and remitted to tax authorities (such as value added taxes, sales taxes or goods and service taxes) are excluded. Interest rate is real interest rate, i.e. the lending interest rate adjusted for inflation as measured by the GDP deflator. Lending rate represents the bank rate that usually meets the short- and medium-term financing needs of the private sector. This rate is normally differentiated according to creditworthiness of borrowers and objectives of financing. The terms and conditions attached to these rates differ by country, however, limiting their comparability. Consumer price index Inflation: we use consumer prices (annual \%); that is inflation as measured by the consumer price index reflects the annual percentage change in the cost to the average consumer of acquiring a basket of goods and services that may be fixed or changed at specified intervals, such as yearly. Real effective exchange rate index $(2010=100)$ is the nominal effective exchange rate (a measure of the value of a currency against a weighted average of several foreign currencies) divided by a price deflator or index of costs.

Household final consumption expenditure per capita growth (annual \%) is annual percentage growth of household final consumption expenditure per capita, which is calculated using household final consumption expenditure in constant 2005 prices and World Bank population estimates. Household final consumption expenditure (private consumption) is the market value of all goods and services, including durable products (such as cars, washing machines, and home computers), purchased by households.

\subsection{Estimations}

Any change in informal sector is supposed to have its full effect on nominal variables like wage. The dependent variable is the average real wage of the entire economy. Our key independent variable is size of informal sector, measure by two different approaches: GDP7 per capita and percentage of informal employees. The others explanatory variables are, tax rate, interest rate, consumer price index, effective exchange rate, final consumption expenditure. We work in short-run and long-run, and all variables are specified in logarithms.

Table 2 and 3 reports our main results. The Tables presents,

6 Informality in employment has always been a challenge for statistical measurement. Detailed statistics are available at: http://laborsta.ilo.org/informal_economy_E.html; ILO, Department of Statistics.

7 See Schneider and Klingmair (2003), and Chong and López-de-Silanes (2004) for some theoretical discussions.
Two-Stage Least Squares (2SLS) IV and the Arellano and Bond GMM one step (henceforth, GMM) estimates of the coefficients, using the macroeconomic-level panel data. One advantage is that a wide range of specifications may be viewed as specific cases in the GMM framework. For example, the simple 2SLS estimator, using ordinary estimates of the coefficient covariance. The choices available for covariance calculation are also available for weight calculations in the standard panel GMM. The data used in all regressions are weighted using the sample weights.

To controlling for a full set of country and year fixed effects, we use an instrumental variables strategy to overcome omitted variable bias. We constructed an instrument for the change in informal sector, "predicted informality", which is calculated from initial informality by level of GDP per person employed, based on regional waves of informalisations and reversals. Our identification assumption is that informalisation in a country spreads to other less developing countries in the panel, but does not have a direct differential impact on wage in these countries (at least conditional on lagged levels of country and regional real wage, and various covariates that could be correlated with country-level real wage at the year, region and initial informality level).

Our main linear regression model takes the form:

$$
\begin{aligned}
\Delta\left(\frac{w}{p}\right)_{i t}= & \sum_{j}^{p} \theta_{j}\left(\frac{w}{p}\right)_{i t-j}+\beta_{1} \Delta y_{i t}+\beta_{2} \Delta L_{i t} \\
& +\gamma \Delta X_{i t}+\mu_{i}+\tau_{t}+\varepsilon_{i t},
\end{aligned}
$$

where $\left(\frac{w}{p}\right)_{i t}$ is the logarithm of real wage in country $i$ at time $\mathrm{t}, y_{i t}$ is the size of informal sector measured by GDP (approach 1), $L_{i t}$ is the percentage of employees in informal sector (approach 2), $X_{i t}$ represent the other independent variables, while the $\mu_{i}$ 's denote a full set of country fixed effects and the $\tau_{t}$ 's denote a full set of year effects. The error term $\varepsilon_{i t}$ includes all other unobservable shocks to real wage. $\Delta$ is operator of first differences.

To facilitate comparison with models that control for the effect of predicted informality, column 1 of Table 2 reports the first estimate using 5-years observations. The standard errors8 in this and subsequent models are robust and allow for arbitrary serial correlation at the country level. Our empirical analysis shows an elasticity coefficient equal 0.403 , with a standard error of 0.790 , indicating a negative impact of informal sector on real wage. Under assumption 1, if the wage effect of formalisation is weaker (i.e., less negative), it is easy to substitute labor and capital. This substitution will lower the real wage. But if labor and capital are easily substitutable, the effective magnitude of the informalisation-induced supply shock will be also smaller for any particular informal worker influx. The magnitude is given by the coefficient associate with percentage informal employees: -0.083 . Otherwise, this coefficient is still

8 In all cases, we use robust standard errors clustered at the level of the listed countries. 
significantly less than 1 (see Table 3, column 1).

To obtain the empirical long-run impact (for a permanent change in wage), we need to compute 9 the sum of these effects over time, which is given by $\frac{\widehat{\beta}}{1-\sum_{j}^{p} \widehat{\theta}_{j}}$. Applying this last formula to the estimates from column 2, we find the long-run effect as 5.59, meaning informalisation increases real wage by $5.6 \%$ in the long-run (and the p-value underneath this number indicates that this estimate is statistically different from zero at the $1.1 \%$ confidence level).

Column 2 adds a second lag of real wage to this specification, and shows that both lags are highly statistically significant and point to richer dynamics (with the first lag being positive and greater than 1, while the second one is negative). But the sum of the two lags, shown also in the wage persistence row at the bottom, is close to that found in column 1. The effect of informality is slightly lower but still highly significant, 0.093 (standard error $=0.18$ ). Correspondingly, the long-run impact is now smaller and more plausible, indicating a $14.9 \%$ increase in real wage in the long-run.

Column 3, which is our preferred specification, includes three lags of real wage. The overall pattern is very similar, with both the degree of persistence and the long-run effect being very close to their estimates in column 2 . In particular, the coefficient of informality is -0.679 (standard error $=0.71$ ) and the long-run impact is a $18.6 \%(p$-value $=0.000)$ increase in real wage following a informalisation. These robust, clustered standard errors are in fact quite close to non-robust, non-clustered standard errors, which supports the conclusion that our estimates successfully model wage dynamics. More conservatively, it is possible to compute standard errors robust to serial correlation within a region $\times$ initial informality $\times$ year cell, which are similar but slightly larger than those reported here. For example, the standard error for the informality coefficient in this case is 0.030 .

The last column of Table 2 reports various GMM estimators that are consistent for finite time dimension. We report estimates from the same model reported in preceding columns. Consistent with our expectations that the within estimator has at most a small bias, the GMM estimates are not very similar to our baseline results. The only notable difference is that GMM models have consistently slightly smaller persistence, leading to somewhat smaller long-run effects. For example, column 4, corresponding to our preferred specification in column 3 , estimates a long-run impact of $9.1 \%$ increase in real wage following an informalisation.

We now examine the wage effect of price, tax rate, exchange rate, interest rate (assumption 3) and consumption (assumptions 4 and 5). Those fourth characteristics are assumed to be important in determining real wages, and there are marked differences between countries in terms of individuality.

As predicted by assumption 3 in the model above, the interest rate variable is positively and statistically significant linked with the wage rate when estimating the size of the

9 This formula is written for the general case with several lags on the right-hand side. informal sector using the first approach as shown in regression 4, Table 2 (in which the wage effect of informalisation is stronger). The cut back effect on demand is confirmed by the negative effect of price on wage in the regression 1, 2, and 3, Table 2 .

We follow an analogous procedure to compute estimates for the second approach in which the size of informal sector is measured by percentage of informal employees. We estimate model 19 using the within estimator (corresponding to column 2 of Table 2), with the same external instruments. Furthermore, as predicted by assumption 4 and 5, we find that there is a positive and statistically significant relationship between consumption and the real wage.

The results for most of these variables are not as clear-cut as our baseline findings for real wage. We also obtain broadly consistent negative estimates for the effect of informality and tax rate on real wage, but results obtained though the GMM estimates are not precise and the semi-parametric estimates show a smaller and imprecise coefficient for the percentage of informal workers and a tapered effect for tax rate. In several cases, there are not noteworthy differences between the four estimators (the three in Table 2 and the GMM). The only variables for which we haven't consistent results with all four estimators are the interest rate and final consumption expenditure. In addition, for first, second and three lagged real wage, we have two of the estimators showing preciselyestimated results and two of them showing less well estimated effects.

Overall, we take these results as suggesting that informality might be working through a number of channels, in particular, by encouraging economic reforms, increasing market flexibility (especially for labour market), and raising capital mobility and some aspects of public services (especially related to taxation) as well as, to some degree, increasing investment and reducing interest rate. Of course, our strategy does not allow us to conclusively establish that these are the most important mechanisms, but the fact that these variables increase following a informality even controlling for lags of real wage suggests they are prime candidates for the channels through which informality might be causing higher wage in long-run.

\section{Concluding Remarks}

This paper completes the literature by examining the wage effects of informal sector in developing countries during 1990-2015. The analytics framework is based on a crucial insight of the factor demand framework that the effect of informalisation on the average wage level depends on factors that are completely different than the factors that determine the distributional effect of informalisation (i.e., the effect of informalisation on the relative wage of different groups of workers). In particular, the parameters that Marshall identified in his famous rules of derived demand (i.e., the elasticity of substitution between labor and capital, the supply elasticity of capital, the elasticity of product demand, and labor's share of income) jointly determine the impact of informalisation on the average wage level. The impact of immigration on the size of the consumer base relative to its 
impact on the size of the workforce is also show. We demonstrate that an imbalance between the impact of informalisation on the size of the consumer base and its impact on the size of the workforce can generate long-run wage effects.

We have focused on the overall effect of informal in wage, which includes production, informal labor, price, consumption, etc., as well as macroeconomic effects (tax rate interest rate or GDP). We agree that the market mechanism may lead to a positive effect of informal sector on wage in the short-run, particularly since the capital adjustment in the presence of the informal worker influx may take years to realize. Our major findings is that the short-run wage effect of informalisation is negative and numerically significant, even after accounting for a wide array of informalisation -induced feedback and scale effects. The long-run reveals an increase effect.

\section{Appendices}

Table 1. Summary statistics (Listed countries level variables).

\begin{tabular}{lllll}
\hline & Mean & Std. dev. & Min & Max \\
\hline $\begin{array}{l}\text { Real wage } \\
\begin{array}{l}\text { Percentage of informal } \\
\text { employees }\end{array}\end{array}$ & 34.7 & 18.9 & 19 & 412 \\
$\begin{array}{l}\text { Gross domestic product } \\
\text { Tax rate }\end{array}$ & 56.2 & 9.5 & 33.0 & 90.4 \\
$\begin{array}{l}\text { Interest rate } \\
\text { Inflation consumer price }\end{array}$ & 23.4 & 11.6 & 13.5 & 339.1 \\
$\begin{array}{l}\text { Effective exchange rate } \\
\text { index }\end{array}$ & 12.3 & 5.6 & 0.1 & 34.5 \\
$\begin{array}{l}\text { Final consumption } \\
\text { expenditure }\end{array}$ & 78.8 & 45.0 & 66.8 & 112.5 \\
\hline
\end{tabular}

Source: World Bank and ILO data updated in 2015.

Table 2. Effect of informal sector in real wage, controlling directly for the impact of informal sector approach 1, using balanced panel data.

\begin{tabular}{lllll}
\hline & $\mathbf{2 S L S}$ & & & GMM \\
\cline { 2 - 5 } & $\mathbf{( 1 )}$ & $\mathbf{( 2 )}$ & $\mathbf{( 3 )}$ & $\mathbf{( 4 )}$ \\
\hline Constant & 0.112 & 0.077 & 0.365 & 0.183 \\
& $(0.08)$ & $(0.07)$ & $(0.27)$ & $(0.24)$ \\
Real wage first lag & $0.456^{* *}$ & -0.009 & -0.010 & $-0.007 * *$ \\
Real wage second & $(0.12)$ & $(0.06)$ & $(0.41)$ & $(0.40)$ \\
lag & $-0.015^{* *}$ & $0.065^{* *}$ & $0.087 *$ & $0.098^{* *}$ \\
Real wage third lag & $(0.01)$ & $(0.02)$ & $(0.11)$ & $(0.30)$ \\
Gross domestic & & $0.093^{*}$ & $0.099 *$ & \\
product & $-0.403 * *$ & $-0.380 *$ & $-0.679 * *$ & $-0.962 * *$ \\
Tax rate & $(0.79)$ & $(0.20)$ & $(0.71)$ & $(2.44)$ \\
& $-0.320 * *$ & -0.014 & -0.035 & $0.079 * *$ \\
Interest rate & $(0.03)$ & $(0.02)$ & $(0.07)$ & $(0.12)$ \\
Inflation consumer & $0.358^{* *}$ & $1.399 * *$ & $1.093 * *$ & $5.298^{* *}$ \\
price & $(0.16)$ & $(0.45)$ & $(0.41)$ & $(1.13)$ \\
Effective exchange & $-0.104 * *$ & -0.004 & -0.025 & $0.376^{* *}$ \\
rate index & $(0.02)$ & $(0.04)$ & $(0.06)$ & $(0.12)$ \\
Final consumption & - & $-0.268^{* *}$ & - & $-1.043 * *$ \\
expenditure & $0.263 * *$ & $0.225 * *$ & 0.186 & 0.171 \\
Countries & $(0.12)$ & $(0.11)$ & $(0.32)$ & $(0.27)$ \\
Periods & 47 & 47 & 47 & 47 \\
Moments & 5 & 5 & 5 & 5 \\
\hline & - & - & - & 25 \\
\hline
\end{tabular}

\begin{tabular}{lllll}
\hline & \multicolumn{2}{l}{ 2SLS } & & GMM \\
\cline { 2 - 5 } & $\mathbf{( 1 )}$ & $\mathbf{( 2 )}$ & $\mathbf{( 3 )}$ & $\mathbf{( 4 )}$ \\
\hline Hansen p-value & - & - & - & 0.29 \\
AR2 p-value & - & - & - & 0.22 \\
\hline
\end{tabular}

Note: $*=$ significant at $5 \%, * *=$ significant at $10 \%$.

2SLS specifications (columns 1, 2, 3) include a full set of country and year fixed effects. Arellano and Bond's GMM estimator (column 4) removes country fixed effects by taking first differences (hence the lower number of time periods), and then constructs moment conditions using all predetermined lags of real wage and predicted informality as instruments. It is estimated in two steps and thus is optimally weighted.

Robust standard errors corrected for arbitrary serial correlation (clustered) at the country level are reported in columns 1, 2, 3, and robust standard errors are reported in column 4.

Table 3. Effect of informal sector in real wage, controlling flexibly for the impact of informal sector approach 2, using balanced panel data.

\begin{tabular}{|c|c|c|c|c|}
\hline & \multicolumn{3}{|l|}{ 2SLS } & \multirow{2}{*}{$\begin{array}{l}\text { GMM } \\
(4) \\
\end{array}$} \\
\hline & (1) & (2) & (3) & \\
\hline Constant & $\begin{array}{l}0.394 * * \\
(0.15)\end{array}$ & $\begin{array}{l}-0.351 \\
(0.34)\end{array}$ & $\begin{array}{l}-0.560 \\
(0.57)\end{array}$ & $\begin{array}{l}-2.586^{* *} \\
(0.99)\end{array}$ \\
\hline Lagged real wage & $\begin{array}{l}0.015 \\
(0.02)\end{array}$ & $\begin{array}{l}0.009 \\
(0.02)\end{array}$ & $\begin{array}{l}-0.026 \\
(0.06)\end{array}$ & $\begin{array}{l}-0.089 \\
(0.06)\end{array}$ \\
\hline Real wage second lag & & $\begin{array}{l}0.017 \\
(0.01)\end{array}$ & & \\
\hline Real wage third lag & & & $\begin{array}{l}0.037 \\
(0.05)\end{array}$ & $\begin{array}{l}0.061^{*} \\
(0.09)\end{array}$ \\
\hline $\begin{array}{l}\text { Percentage informal } \\
\text { employees }\end{array}$ & $\begin{array}{l}-0.083^{*} \\
(0.67)\end{array}$ & $\begin{array}{l}-0.075 \\
(0.65)\end{array}$ & $\begin{array}{l}-0.054 \\
(1.87)\end{array}$ & $\begin{array}{l}0.070 \\
(1.77)\end{array}$ \\
\hline Tax rate & $\begin{array}{l}-0.065 \\
(0.68)\end{array}$ & $\begin{array}{l}-0.084 \\
(0.70)\end{array}$ & $\begin{array}{l}-0.044 \\
(1.23)\end{array}$ & $\begin{array}{l}0.079 \\
(1.11)\end{array}$ \\
\hline Interest rate & $\begin{array}{l}-0.107 * * \\
(0.02)\end{array}$ & $\begin{array}{l}0.080 \\
(0.07)\end{array}$ & $\begin{array}{l}-0.007 \\
(0.06)\end{array}$ & $\begin{array}{l}0.596 * * \\
(0.22)\end{array}$ \\
\hline $\begin{array}{l}\text { Inflation consumer } \\
\text { price }\end{array}$ & - & $\begin{array}{l}-0.489^{* *} \\
(0.17)\end{array}$ & - & $\begin{array}{l}-1.517 * * \\
(0.48)\end{array}$ \\
\hline $\begin{array}{l}\text { Effective exchange } \\
\text { rate index }\end{array}$ & $\begin{array}{l}0.315^{* *} \\
(0.14)\end{array}$ & $\begin{array}{l}0.274 * * \\
(0.13)\end{array}$ & $\begin{array}{l}0.295 \\
(0.40)\end{array}$ & $\begin{array}{l}0.286 \\
(0.36)\end{array}$ \\
\hline Final consumption & 0.082 & 0.055 & 0.368 & 0.220 \\
\hline expenditure & $(0.09)$ & $(0.09)$ & $(0.27)$ & $(0.25)$ \\
\hline Countries & 47 & 47 & 47 & 47 \\
\hline Periods & 5 & 5 & 5 & 5 \\
\hline Moments & - & - & - & 24 \\
\hline Hansen p-value & - & - & - & 0.31 \\
\hline AR2 p-value & - & - & - & 0.43 \\
\hline
\end{tabular}

Note: $*=$ significant at $5 \%, * *=$ significant at $10 \%$.

\section{References}

[1] Badaoui, E., Strobl, E. and Walsh, F. (2010), The Formal Sector Wage Premium and Firm Size, Journal of Development Economics, 91(1): 37-47.

[2] Blunch, N.-H., Canagarajah, S., and Raju, D. (2001), The Informal Sector Revisited: A Synthesis across Space and Time, unpublished, World Bank.

[3] Carneiro, F. G. and Henley, A. (1998), Wage Determination in Brazil: the Growth of Union Bargaining Power and Informal Employment, Journal of Development Studies, 34(4): 117-138. 
[4] Chong, A. and López-de-Silanes, F. (2004), Money Laundering around the World, Washington, D. C., United States: Inter-American Development Bank, Manuscript.

[5] Dickens, W. and Lang, K. (1985), A Test of the Dual labor Market Theory, American Economic Review, 75(4): 792-805.

[6] Dixit, A. and Norman, V. (1980), The Theory of International Trade: A Dual, General Equilibrium Approach, Cambridge University Press.

[7] Fields, G. S. (1975), Rural-Urban Migration, Urban Unemployment and Underemployment, and Job Search Activity in LDCs, Journal of Development Economics, 2: 165187.

[8] Ghose, A. K. (2003), Jobs and Incomes in a Globalizing World, International Labour Office, Geneva.

[9] Hamermesh, D. (1993), Labor Demand, Princeton University Press.

[10] Henley, A., Arabsheibani, G. R. and Carneiro, F. G. (2007), On Defining and Measuring the Informal Sector, Policy Research Working Paper, 3866, World Bank.

[11] Heintz, J. and Pollin, R. (2003), Informalization, Economic Growth and the Challenge of creating viable Labor Standards in Developing Countries, Working Paper, 60, Political
Economy Research Institute, Amherst, MA.

[12] Hicks, J. R. (1932), The Theory of Wages, London: Macmillan.

[13] Kennan, J. (1998), The Hicks-Marshall Rules of Derived Demand: An Expository Note, University of Wisconsin, Madison.

[14] Marjit, S. and Maiti, D. (2006), Globalization, Reform and Informal sector, in Guha Khasnobis, B and Kanbur, R. (eds), Informal Labor Markets and Development, UK: McMillanPalgrave, 9-28.

[15] Pemberton, J. (1989), Marshall's Rules for Derived Demand: A Critique and Generalisation, Scottish Journal of Economics, 36(4): 396-405.

[16] Rufer, T. and Knight, J. (2007), Informal Sector Labor Markets in Developing Countries, University of Oxford.

[17] Schneider, F. and Klingmair, R. (2003), Shadow Economies around the World: What do we know?, Linz-Auhof, Austria: Johannnes Kepler University, Manuscript.

[18] World Bank (1996), World Development Report, Washington, DC: World Bank. 